\title{
Correction to: Identifying the barriers to universal cervical length screening for preterm birth prevention at a tertiary hospital in Thailand (patient's perspectives): implementation research
}

\author{
Saifon Chawanpaiboon ${ }^{1}$ (D) Vitaya Titapant ${ }^{1} \cdot$ Sanitra Anuwutnavin ${ }^{1} \cdot$ Attapol Kanjanapongporn $^{2}$. \\ Julaporn Pooliam ${ }^{3}$
}

Published online: 29 April 2021

(c) Springer-Verlag GmbH Germany, part of Springer Nature 2021

\section{Correction to: Archives of Gynecology and Obstetrics https://doi.org/10.1007/s00404-021-06045-3}

In the original article published, the name of the third author is incorrect. The correct name is Sanitra Anuwutnavin.

The original article has been corrected.

Publisher's Note Springer Nature remains neutral with regard to jurisdictional claims in published maps and institutional affiliations.

The original article can be found online at https://doi.org/10.1007/ s00404-021-06045-3.

\section{Saifon Chawanpaiboon}

saifon.cha@mahidol.ac.th

1 Division of Maternal-Fetal Medicine, Department of Obstetrics and Gynaecology, Faculty of Medicine Siriraj Hospital, Mahidol University, Bangkok 10700, Thailand

2 Department of Social Sciences, Faculty of Social Sciences and Humanities, Mahidol University, Nakhon Pathom 73170, Thailand

3 Clinical Epidemiological Unit, Office for Research and Development, Faculty of Medicine, Siriraj Hospital, Mahidol University, Bangkok 10700, Thailand 